\section{A welcome change}

Sir, on 27 July 2020, the Department of Health and Social Care published a new obesity strategy aiming to improve the nation's health. ${ }^{1}$ This comes at a time when evidence has linked those with excess weight to being at a greater risk of serious illness or death from COVID-19.

Amongst a number of new measures, the strategy includes a ban on TV and online adverts before $9 \mathrm{pm}$ for foods high in fat, salt and sugar. This is great news for young children who would otherwise be bombarded with inappropriate adverts for junk food. Hopefully these new measures will have a domino effect on the oral health of children by reducing sugar consumption and the incidence of dental caries.

\section{O. J. Ehsan, Manchester, UK}

\section{Reference}

1. GOV UK. Press release: New obesity strategy. Available at https://www.gov.uk/government/news/new-obesity-strategy-unveiled-as-country-urged-to-lose-weightto-beat-coronavirus-covid-19-and-protect-the-nhs (accessed July 2020).

https://doi.org/10.1038/s41415-020-2006-8

\section{Special care in UDCs}

Sir, as a specialist registrar in training in special care dentistry I have been working in an urgent dental care (UDC) hub providing care for shielded, vulnerable and COVID positive patients in a rural county.

We have had a considerable number of patients referred to the UDC with significant complex medical conditions and medication regimes. Referrals have included pre-transplant patients, oncology patients undergoing active treatment, complex liver and kidney disease, an array of rare diseases and numerous rheumatology patients taking a range of disease modifying medications.

Many patients have required additional blood tests, investigations and medication reviews prior to undertaking dental treatment inevitably requiring communication with multiple medical specialities. A great majority would have benefited greatly from a dental examination prior to starting treatments such as bisphosphonates, chemotherapy or radiotherapy. Many are now in a compromised position where risks of conditions such as medication-related osteonecrosis of the jaw is high. The patients themselves have often had little knowledge about the importance of optimising their dental health as part of their medical condition and some have not accessed dental care for many years.

This experience has highlighted that dentistry plays an important role within the integrated care system but is currently often overlooked. As we look to the future, and the restoration of dental services, the profession needs to work with stakeholders to ensure that the importance of oral health as part of holistic healthcare is fully understood and high on the public health agenda.

A. Hughes, Derbyshire, UK https://doi.org/10.1038/s41415-020-2007-7

\section{Open-book examinations}

Sir, the UK curricula in dentistry is set by the General Dental Council with universities required to provide assurances that intended learning objectives (ILOs), clinical and nonclinical milestones and competencies have been satisfactorily achieved. Assessments in these courses are longitudinal and end of year examinations assess different sections of the ILOs to demonstrate evidence-based practice in clinical scenarios and decision making mirroring the clinical environment.

Traditionally, closed book examinations such as multiple-choice questions, where learners are not permitted to have any supportive material with them, are the preferred format for UK dental courses. The COVID-19 national lockdown resulted in re-structuring of assessments to open-book formats so learners could complete their examinations at home and has provided a novel opportunity to reflect on examination practices. ${ }^{1}$

In open-book examinations, learners have access to supportive material such as revision notes, books and online resources thereby testing the application of knowledge rather than its recall. ${ }^{2}$ Studies have shown that learners revising for open-book examinations prepare by proactively understanding the content and its application for problem solving, thereby encouraging deep learning. ${ }^{3}$ Learners have also reported feeling less anxious about exam preparation, which is reflected in significantly higher test scores. ${ }^{4,5}$ Nonetheless, these examinations can test information retrieval rather than knowledge and this is a well-recognised limitation. More research is required to determine if open-book examinations are suitable formats for end of year assessments and to optimise curriculum development and learner experiences.

M. Dave, S. Ariyaratnam, C. Dixon, N. Patel, Manchester, UK

\section{References}

1. Tapper J, Batty D, Savage M. Medical students take final exams online for first time, despite student concern. The Guardian 22 March 2020. Available at: https://www. theguardian.com/education/2020/mar/22/coronavirus-forces-medical-students-sit-final-exams-online (accessed 11 April 2020)

2. Heijne-Penninga M, Kuks J B M, Hofman W H A, Cohen-Schotanus J. Influence of open- and closed-book tests on medical students' learning approaches. Med Educ 2008; 42: 967-974.

3. Agarwal P K, Karpicke J D, Kang S H K, Roediger lii H $\mathrm{L}, \mathrm{McD}$ ermott K B. Examining the testing effect with open- and closed-book tests. App/ Cognitive Psych 2008 22: 861-876.

4. Lipner R S, Brossman B G, Samonte K M, Durning S J. Effect of access to an electronic medical resource on performance characteristics of a certification examination: A randomized controlled trial. Ann Intern Med 2017; 167: 302-310.

5. Bobby Z, Meiyappan K. 'Test-enhanced' focused self-directed learning after the teaching modules in biochemistry. Biochem Mol Biol Educ 2018; 46: 472-477. https://doi.org/10.1038/s41415-020-2008-6

\section{Anosmia and ageusia}

Sir, loss of smell (anosmia) and loss of taste (ageusia) are symptoms that were identified in COVID-19 patients at the early stage of illness. ${ }^{1}$ These symptoms may last from a few days to few weeks and may be associated with continuous viral shedding. ${ }^{2}$

Dental professionals should be aware that the continuous impairment of olfactory and gustatory functions after 14 days of quarantine and onset of the symptoms may indicate incomplete recovery, that a recently recovered COVID-19 patient may still be carrying the viral load and risk of virus transmission should not be excluded. With such an hypothesis in mind, it is recommended to postpone dental treatment of a recently recovered COVID-19 patient who still suffers from these persistent symptoms until complete resolution.

B. Tarakji, F. M. Alali, Al Kharj, Saudi Arabia; M. Z. Nassani, Riyadh, Saudi Arabia

\section{References}

1. Song J Y, Yun J G, Noh J Y, Cheong H J, Kim W J. Covid-19 in South Korea - Challenges of subclinical manifestations. N Engl J Med 2020; 382: 1858-1859.

2. Noh J Y, Yoon J G, Seong $\mathrm{H}$ et al. Asymptomatic infection and atypical manifestations of COVID-19: Comparison of viral shedding duration. J Infect 2020; S01634453(20)30310-8. doi:10.1016/j.jinf.2020.05.035. https://doi.org/10.1038/s41415-020-2009-5 